Departamento de Indústria, Inspeção e Conservaçãa de Produtos Alimentícios de Origem Animal

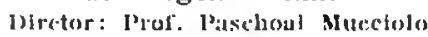

Departamento de Microbiologia e Imunologia Dirrater: Prof. Ermesto de Sonya Compos

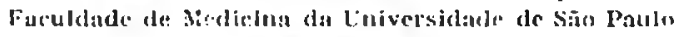

\title{
PENICILIOSE EM QUEIJOS
}

\author{
(PFNICIILIOSIS IN CHEESE)
}

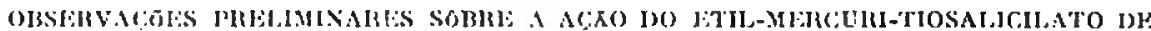

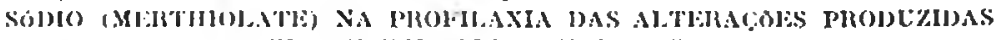

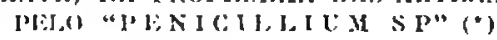

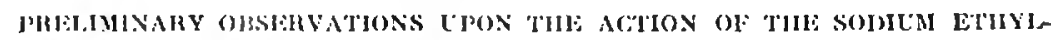

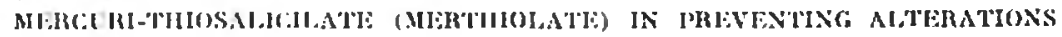
l'RODMEEH BY THE "PENICII,LIL M SW."

\section{$\begin{array}{lll}\text { P. Mucciolo } & \text { C. S. Lacaz } & \text { P. Assis Ribeiro }\end{array}$ \\ Livre Docente \\ Assistente \\ I col:ampas (6 rignuras)}

Quasi torlos os produtos alimentícios estão sujeitos à contaminação por bolores quanto mantidos por muito tempo em más condiçóes de comecrvação. Nas contaminaçoos maciças, os cogumelos modificam os caractéres físicos, químicos e organoléticos dos alimentas, o que justifica a conduta do veterinário-inspetor em afastar do consumo público produtos assim alterados. Quando as contaminações são discretas, nãc chigando a comprometer a salubridade dos alimentos, o próprio consumidor incumbe-se de regeitá-los, devido à repugnância que os mesmos ihe despertam.

Não há até o momento, para a maioria dos cogumelos banais de contaminasiono, qualquer base ciêntífica que elucide sôbre sua possivel nocividade parai a saúde humana, quando ingeridos com os alimentos. Nessa ordem de idéias, convém referir que as experiências realizadas no Colégio Estadual de Dakota do Sul, nas Lniversidades de Purdue e de Illinois jor diversos investigadores (JoHnson, roHNSON e Wrigtir, Smonsen, louke e (ARrick) citados no editorial do Jour. Am. Vet. Med. Ass. de Novembro de 1946, näo conseguiram demonstrar qualquer cfeito déctério para a saúde de bovinos, ovinos, suínos e aves alimentados, por longo tempo, com alimentos mofados.

No calio do hite e derivados, normalmente são encontrados certos cogumelos, como o Oospora lactis, cuja presenca no leite azêdo, no creme e em outros laticinios foi verificalla por MaCY e ANDERson e $22-28 / 1 / 19$ is. 
posteriormente por ELLIKER. Outros cogumelos (Penicillium roqueforti, $P$. camemberti e $P$. gorgonzola) são propositadamente incorporados à massa de queijos com o objetivo de sc obterem fermentacões especiais, conferindo-lhes assim, em resultado, textura e sabor peculiares, que caracterizam tais tipos de produtos. Entretanto, existindo no ambiente esporos de cogumelos largamente distribuidos, são encontrados nos laticínios bolores absolutamente indescjáveis, quase sempre devido à falta de higiêne na manipulação dos produtos, como mostraram ALMEIDA, LACAZ e Ribeiro do VALE ou porque, como refere MALlinan, a própria matéria prima traz a contaminação para a fábrica.

F' verdade que nem todos os alimentos oferecem idênticas condiçôes para o desenvoivimento de cogumelos; alguns, como os queijos, apresentam substâncias nutritivas mais satisfatórias enłuanto outros, como a manteiga e o creme, quer pelo fraco teor $\mathrm{cm}$ lactose e umidade, quer pela elevada taxa de gordura e sal (cloreto de sódio), não favorecem tal crescimento (HAMMER). Mesmo assim, a quantidade de filamentos micelianos presentes no creme $\mathrm{c}$ na manteiga constitue indice para se aferir da qualidade desses alimentos, dispondo o analista de testes especiais, como os de Wildman, Ellikfr, M. B. B. (methylene-biuc-borax) cujos resultedos são expressos en percentagem de campos examinados que mostraram micćlios (BÜLIfRs SOLTO e al., Elliker e JIorrall, Elliker). Realmente, como observou liegigatt, a presença de bolores e leveduras na manteiga indica a necessidade de melhorar as condiçōes sanitárias de fabricação.

Dentre os muitos fatores que condicionam o aparecimento de cogumelos nos latícinios, como na gencraiidade dos alimentos, rlestacam-se: umidade, temperatura, idade, acidez, taxa de sal, obscuridade, aeraçāo.

A umidade é imprescindivel e dai proliferarem os bolores muito mais facilmente nos produtos que retêm grande teor de água. F' assim ciue, como diz MaldMaN, a umidade é essencial para a germinação dos esporos e condição favorável no particular é a formação de um filme de umidarle na superficie do alimento e seus envoltórios.

ADAMS e PARFTT, de suas experiências, concluiram que a quantidade de micé!lios na manteiga estava na razio inversa da idaile e da temperatura de conservação do creme usado como matéria prima. A idênticas conclusões, quanto à influêneia da temperatura sôbre at ]roliferaçĩo micótica, chegaram REID, TMMONDSON e ARBUchle e MAcY e ANDEeson verificando, entretanto, êstes úitimos autores, que as temperaturas baixas só têm ef́eito inibidor permanente quando o $\mathrm{pH}$ 
fôr baixo. E' claro que falam em têrmos gerais porque é sabido que os Penicillium crescem bem a temperaturas baixas.

Segundo MACY e ANIERSON o gráu de acidez não tem por si só efcito notável sôbre a exuberância do crescimento dos mofos. Contudo, das experiências de EldLIKER depreendes-se que à jroliferação dos bolores é inibida pela aciclez elevada, opinião esta que é cornpartilhada por JACOIs.

Quanto à taxa de sal (cloreto de sódio), as concentrações elevadas dificuitam ou mesmo impedem o desenvolvimenio da flora micótica. MACY e ANDERSON observaram que em culturas de agar-sôno o crescimento de Oosporu lactis era afetado quando o teor salino ultrapassava $1 \%$ e era inteiramente impedido numa concentraçāo a $10 \%$, enquanto nas culturas em !eitciho a ação impediente começava a manifestar-se quando a proporção de sal atingia $2,5 \%$.

A obscuridade é favorável aos cogumclos, indubitivelmente devido, em parte, à falta cie radiação ultra-violeta e, em parte, ao maior teor de umidade dos locais nâo ensolarados.

As condiçōes de aerobiose são mais propicias ao descnvolvimento dos bolores, se bem que algumas espécies se adatem perfeitamentc is de scmi-anaerobiose. A quantidade de mofos encontrada $\mathrm{cm}$ cada amostra de creme examinada no trabalho executado por ADAMs e PARriTT foi diretamente proporcional à superfícic de exposição. As experiências já citadas de ELLIKER evidenciaram que a ausência de ar inibe o crescimento die Oospora lactis. 'Tambem Goldivg, procurando verificar d: exigências em oxigênio de três amostras de Penicillium roqueforti, concluiu que uma redução significante no crescimento exa obtida em atmosferas com as maiores diuições desse elemento.

E' claro que, sendo muitas as fonies de onde pódem provir as contaminaçốs, impốcm-se rigorosas medidas de combate aos cogumelos, devendo os laticinistas, como aconselha MACY, fixar sua atenção sôbre todos os detalhez das opereções, desdo a saída do leite da fazenda até o produto já industrializado atingir o consumo.

Esquematizando as medidas profiláticas tendentes a diminuir ou mesmo impedir a contaminaçĩo de alimentos por cogumelos, ALMEIDA, LACAZ e RiBriko do vaLE preconizam as seguintes normas:

“a) assegurar esterilidarie relativa ao ambiente onde se trabalha, mantendo as paredes, fôrros e assoalhos bem limpos e sêcos.

b) exercer severa vigilância e contrôlc sobhre as pessôs que prepar:im os produtos, assim como os visitantes;

c) praticar limpeza cuidadosa dos titensílios empregados na manufatura: 
d) praticar a pasteurização dos produtos;

e) limitar o crescimento dos cogumelos por meio de substîncias antisséticas."

Os prejuizos econômicos decorrentes da presença de bolores nos derivados do leite sāo incalculáveis porque a contaminação, comprometendo a qualidade, acarreta a retirada de grancle quantidade de alimentos do consumo, seja pela ação das autoridarles sanitárias, seja pela aversão que o público sente por produtos assim alterados. Considerando-se o extraordinário poder de disseminação e as poucas exigências quanto aos meios de cultura, fácilmente podem ser avaliadas as proporções que assumem as invasōes das indústrias de produtos alimentícios por cogumelos.

\section{ALTERAÇŌES EM QUEIJOS}

Em meados de 1947, queijos dos tipos Minas e Cheddar produzidos pela Fábrica Fscola de Laticínios "Cândido Tostes", em Juiz de Fóra, apresentaram-se com a!terações, até então ali desconhecidas, consistindo de prequenos pontos arroxeados, às vêzes confluindo em manchas maiopes, de bordos irregulares e com a parte central mais intensamente ccrada, cobrindo assim áreas arreciáveis do produto.

Solicitando informaçōes dos técnicos do estabelecimento, conseguimos apurar que o defeito era mais frequente e intenso nos queijos do tipo Minas (parafinado), muito embora outros tipos de massa semicozida (Prato e Cheduar) támbém apresentassem a alteração, porém de modo mais discreto e marcha mais lenta, enquanto se mantinham indenes os queijos de massa cozida (Parmezão). Nos queijos de massa crúa tipo Minas as alteraçoos apareciam cêrca de uma dezena de dias após a paralinagen e nes de massa semi-cozida não parafinados (Chedklar) só após três meses, aproximadamente, de permanência na câmara de cura, tendo sido informados de que, una vez rasnada a parafina dos queijos manchados, o defeito dificilmente voltava a se instalar.

Um exame acurado das salas de fabricação revelou alguns azulejos que auresentavam nauchas de côr idêntici ìs obscrvacias nos queijos. Este fato determinou rigorosa hirrionização do estabelecimento, incluindo caiaçãa de paredes e fôrros com cal extinta e sulfato de cobre, desinfecção do ambiente com $\mathrm{SO}^{2}$ e formaldeido, esterilização de vasilhame, institalações, utensílios e, posteriormente, substituição total de prateleiras e até do revestimento das paredes de salas de salga e de cura. 
A despeito de tão sevcras medidas profiláticas, o defeito se bem que em menor escala, continuou a alparecer cm queijos já em poder do comércio varejista, o que motivou a devolução de algumas partidas ao estabelecimento inclustrial de origem.

Chamados a cooperar no caso, recebemos da Fábrica Escola "Cândido Tostes" material para estudo, consistindo em alguns queijos com alteraçño em diversos grłáus, pedaços de aziilejos e de parafina também portadores de manchas.

P'rocupados, inicialmente, em identificar a natureza das manchas, praticános córtes histológicos nos queijos e semeaduras em agarSabourat e em meio de Czapel. Colhemos o material dos azulejos, de fragmentos de parafinai e dos queijos contaminados c, uma vez semeados, for am os meios deixados à temperatura ambiente. Isolámos então, com lacilidade, um bolor do gênero Penicillium, (LiNk, 1809) espécic não identificada.

Repetimos diversas vêzes as mesmas semeaduras e verificamos que o cogumelo isolado pertencia sempre ao gênero Penicillium. Com a amostra por nós isolada, fizemos inoculações em fragmentos de queijos e dias depois, alteraaçoes experimentais idênticas às encontradas nos outros queijos foram observadas.

A idtentificação da espécic de Penicillium que isolámos não foi tentada, dada a grande dificuldade da referida identificaçāo.

O número de espécies pertencentes ao gênero Penicillium é enorme, razão pela qual deveria ser feito um estudo comparativo, do ponto de vista macro e micromorfológico com outras espécies já bem conhecidas. Por esta razáti, resolvemos enviar uma clas amostras por nós isolada ao Prof. Trom, autor de preciosa monografia sôbre o Penicillium, a fim de que êste micologista se encarrégue da identificação especifica.

A fotografia 1 mostra o aspecto macroscópico do Penicillium isolado dos queijos contaminados.

A colônia do Penicillizin quue isolámos é de coloração esverdeada, apresentando o seu reverso amarelado. Microscònicamente, verificamos a presença de conidióforos típicos do referido gênero.

Entre as alterações de côr dos queijos referidas pelos diversos autores especializados, não encontrámos nenhuma que se identifique precisamente ao caso aqui relatado.

Fleiscimann, citando as análises efetuadas por ADAMETZ, F. J. Herz, Bartinel, Gratz e outros, de colônias de fungos negros, pardos, vermeihos e amarelos observados com maior frequência na casca de diversos tipos de queijos, não inclue o gênero Penicillium na lista de agentes etiológicos. HAMMER, expondo que os bolores encontram 
nos queijos ótimo meio de cultura e neles se désenvolvem quando dispōem de condições favoráveis de umidade e temperatura, lembra que a contaminação aparece principalmente na superfície devido à exigência destes organismos em oxigênio. l'orém, feitas tais consideraçōes de ordem geral, não fa\% aquele autor referências especiais aos gêneros de cogumelos responsáveis pelas alterações. Entretanto, ORLA-JENSEN, depois de tecer pormenorizados comentálios is alterações de côr da massa de diversos tipos de queijos, esclarece que as manchas coradas da casca pódem ser dcvidas, quer a bacterias, quer a mofos, entre os quais enquadra o Penicillium casei. Outros autores como FAsCETti, Ceciria e Olver limitam-se apenas a mencionar que - gênero Punicillium tem papel preponderante em causar alterações de côr da casca dos queijos, não descendo, contudo a minúcias do fato.

\section{PROFILAXIA DA PENICIJIOSE}

Conhecido o aggente etiológico responsável pelas referidas alterações, impunha-se fazer a profilaxia, que devia visar primeiramente o estabelecimento e respectivas instalações e, por último, os produtos.

A higienização do estabelecimento foi feita, como dissemos atrás, pelos técnicos locais e, ao gue soubemos, não podia ter sido mais rigorosa, naturalmente dentro dos recursos postos à sua disposição. Contudo, convém lembrar a título ilustrativo que MALLMAN e MICHAEI, (in Jacobs) desejando prevenir o desenvolvimento de mofos nos frigorificos de ovos, após exaustiva expcriência, obtiveram, em escala comercial, resultados satisfatórios usando vapores de Dowicide G. (pentaclorofenato de sódio). Além dos vapores micostáticos, a profilaxia dos bolores pode ser feita à custa de tintas contendo alto teôr em óxido de zinco, clorofenois, sulfato de hidrcxiquinoleina ou então, como aconselha JaCoBs, clorando o ólco de linhaça do tal forma que a tinta fique com $4 \%$ de halógeno. O pentaclorofenato rle sódio foi também ıttilizado, com ótimos resultados, por BRIEN e DENNE, adicionado ì tinta, na concentração de $2 \%$.

$\mathrm{Na}$ purificação de ambientes, o ozona ocupa lugar de destacque, não obstante ser contraindicado para a conservação de alimentos ricos em gordura que facilmente se tornam rançosos em virtude do alto peder de oxidação desse agcnte. Estas observações, devidas a WaTson, não aconselham o enprego do ozona como fungicida, isto i, na concentração de $0, \AA$ a $2 \%$, para manteigra, creme e queijos gorios por ter aquele autor verificado que tal corpo oxida essas substânciats mais rapidamente do que o prónrio oxigênio.

Em 1036 a Westinghouse Lamp., de New Jersey, lancou no mercado lâmpadas especiais para a esterilização de ambientes a que 
chamou "Sterilamp" cujas radiações se fazem sentir não só sôbre insetos como, principalmente, sçbre bactćrias, bolores e leveduras.

Os resultadios obtidos com essas radiações germicidas foram tāo evidentes que hoje à instalaçāo das "Sterilamp" é de uso quasi obrigatório em salas onde se deseja ambiente esteril.

Tendo sido feita a desinfecção do estabelecimento de que nos ocupamos e de sulas instalações com os recursos disponiveis no monento resolvemos, diante da ineficácia dos mesmos, dirigir a profilaxia para os produtos.

Muitos compostos foram preconizados com o objetivo de prevenir, por contáto diréto, o aparecimento de bolores nos alimentos, mas, hos últimos dez anos, as pesquizas nesse sentido se movimentaram em torno do poder fungistatico demonstrado pelos ácidos graxos, principalmente do ácido propiônico e seus sais que agora já estão sencio aplicados nas indústrias de panificação e de laticínios (JACOBS), incorporados à massa dos produtos ou impregnando os envoltórios dos alimentos.

$\mathrm{O}$ áciclo propiônico, o propionato de cálcio e o propionato de sódio foram inicialmente empregados no tratamento dos envoltórios da manteiga, afim de impcdir o crescimento de bolores na superfície desse alimento. MACY e OLSON conseguiram acentuada inibição no desenvolvimento de cogumelos, quando as mantcigas eram envolvidas em papel pergaminho impregnado com soluções de propionato de sódio ou de cálcio em altas concentrações (até $20 \%$ ). Esses mesmos AA., em traba!ho posterior, observaram gue o ácido propiônico era mais eficiente do que seus sais de sódio ou de cálcio, recuerendo, para igual ação impediente, soluções de muito mais baixa concentração.

E.m 1945, OLSON Jr. e MACY verificaram que uma solução a $5 \%$ de propionato de cálcio acidificada pelo ácido lático a pH 5,5 e utilizada para impregnar panel pergaminhado era tão eficiente em preservar de cogumelos a manteiga quanto uma soluçāo não acidificada desse mesimo sal a $10 \%$.

A litcratura a respeito da profilaxia dos queijos contra o aparecimento de bolores refere também o emprego do ácido propiônico e seus sais de sódio e cálcio e, ainda noste caso, como observaram IRviNe e SProule e Inglek, o ácido propiônico é mais eficiente como micostático que seus sais de cálicio e sódio nas mesmas concentraçũes.

Para Joll Ns a concentração das soluções dos sais, para se obter resultalo positivo, no tratamento cle queijos, vai de 8 a $12 \%$. A justificativa desses fatos, parece-nos ser encontrada por OLSON JR. e 
MaCY que atribuem ìs moleculas não dissociadas do ácido propiônico o papel mais inportante no efeito inibidor do crescimento dos cogumelos.

Un editorial do número de junho de 1942 de National Eutter and Cncese douraal, comentando o emprego do ácido propionico e seus sais nil proteçãa dos láícinios contra a invasão dos b lores, quer pelo tratamento dos envolucros, quer pela adição dirita a massa na fabricaşão, prevê a possibilidade de imergir as fatias de queijo por 15 segundos na solução fungistatica, afim de dilatar o periodo necesciirio à venda nas mercearias.

Devemos referit que com a denominaçio Myroban, a E. 1. Dupont de Nemours Company, lançou no comércio um produto para ser adicionado it massa de pães es bolos, constituida por propionato de sódio ou de cátcio, com a finalidade de inibir o crescimento de bolores.

O propionato de sódio foi empregado por Gonzalez OciroA e Ruizoba por via ora?, no tratamento da actinomicose, não apresentando qualquer manifestação toxica. Na prática, os propionatos de sódio e de cálcio têm sido empruregados no tratamento das infecçōes micóticas superficiais da pele. (KEeney e BRoYLes, Kerney e colanoradores). Nas concentrą̧óes de 10 at $20 \%$, o proprionato de sódio ou de cálcio exerce sua máxima atividade fungistatica.

Diante do que foi sucintamente exposto, seria lógico tentar a aplicação dos propionatos para o caso das alterações que se manifestaram nos queijos produzidos pela Fábrica Esscola "Cândido Tostes". Entretanto, as diversas espécies de cogumelos variam decididamente em sua sucetibilidade em face do tratamento pelos propionatos. Dos estudos já citados de OLSON e MACY quanto à tolerância de diversos gêneros de cogumelos ao ácido propiônico e seus sais de sódio e de cálcio, depreende-se que são os Penicillium os mais tolerantes à ação fungistatica desses compostos. Também OLsoN JR. e RACY, trabalhando com muitos gêneros de cogumelos, puderam confirmar que os Penicillium são marcadamente mais resistentes ao efeito impodiente dos propionatos.

Por outro !ado, as concentracoes elcvadas em que devem ser usados o ácido proplionico e seus sais para se mostrarem eficientes, conduzem a modificações das caractcrísticas organoléticas dos queijos, como foi apontado por diversos autores (IRvine e Sproule, Jonns, F. MILLER).

Foram essiz razões, sem dúvida ponderáveis, porque, como refere GLOBz, os fungistáticos devem, como característica primordial, não aỉetar nem o gôsto nem o cheiro clos produtos trataclos, que nos levaram a escolher outra substância que, sendo realmente eficiente 
em impedir o crescimento do Penicillizm isolado, não interferisse nas qualidardes físico-organoléticas dos queijos.

Nossa atenção voltou-se parà o estudo da atividade fungistática do "Merthiohate", apús a leitura do trabalho de Turneir e Col. que emprecnleram, durante a última guerra, uma série de experiências no sentido de evitar que os instrumentos óticos utilizados pelas forças americanas e inglessas nos países tropicais, sofressem o embolorecimonto. Esse; autores isolararn desses instrumentos, como fungos contaminantes, o Penicillium spinulosum, o P. citrinum, o P. commune, o Asprigillus niger, o 'Trichodevina vivide e o Mucor racemosus. De todas as substâncias quimicas por êles experimentadas, simente o Silimercuritiosalicilato de sódio, conhecido pela indicaçăo "M. T. S." e proparalo na Australia pelo Prof. V. M. Trikojus, apresentou propriedades favoráveis quanto à ação sôbre os diversos fungos contaminantes, quanto à persistência de ação e quanto à ausência de toxicidade para o homem, requisitos que particularmente nos interessam no caso presente.

Devemos referir que este sal já havia sido sintetisado nos Estados Unidos, nos laboratórios de pesquisas dá firma Liily, sendo conhecido no comércio pelo nome de "Merthiolate" (Etilmercuritiosalicilato de sódio - $\mathrm{C}_{3} \mathrm{II}_{5 .} \mathrm{HgS}$. $\mathrm{C}_{4 ;} \mathrm{H}_{4}$. COONa).

o "Nerthiolate" apresonta-se como um pó cristalino, de côr amarelo-clara, encerrando cêrca de $49 \%$ de mercúrio em combinação orgânicá é francamente solúvel em água e água fisiolórica. Suas propriedades germicidas fôram estudadas por POwELL e JAMIESON, Marsiall e outros. E' ele largamente utilisado como prescrvativo de prordutos biológicos e quanto ao indice de toxicidade, aproxima-se do antissético ideal; como reconhecem TURNer e col. é impossível que, nas concentrações em que atua como fungistatico, cause qualquer prejuizo á saúde do homem; de fato, o "Merthiolate" tem largo emprego na clínica, na desinfecção da péle e mucósas, quando em solução aquósa ou tintura a $1: 1.000$.

Marshall já havia verificado que o "Merthiolate", quando diluido a 1:10.000 possuia nitido efeito fungistático sôbre o crescimento clo Coccirlinides immitis, agente do granuloma coccidioidico e sôbre o Trichophyfon inturdigitulis, um dos agentes de dermatofitóse. Almidn e col., verificaram que o "Merthiolate", em diluição de $1: 20.000$, apresentava evidente ação fungistatica sôbre o crescimento do Parecoccidinides brasiliensis, agente da blastomicose sul-americana.

F.uses estudos levaram-nos a ensaiar "in vitro" a ação do "Merthiolate" sôbre o Penicillium produtor das alteraçous de queijos fabricados na Fábrica Escola "Cândido Tostes"; con esse objetivo, 
semeamos o Penicillium em tubos de caldo Sabouraud aos quais prèviamente adicionamos o "Herthiolate" nas concentraçóes assinaladas no quadro abaixo.

\begin{tabular}{l} 
AÇAO DO "MERTHIOLATE" "IN VITLO" \\
Gráo de crescimento $\left\{\begin{array}{c}1: 100.000 \\
++\end{array}\right.$ \\
\hline
\end{tabular}

Os resuitados observados dez dias após a semeadura evidenciaram que o "Merthiolate", mesmo na diluição de 1:50.000, impede "in vitro" o crescimento do P'enicillium.

CAPACIDADE INIBIDORA DA MESMA CONCENTRAÇĀO DE "MERTHIOLATE" PARA VARIOS COGUMELOS

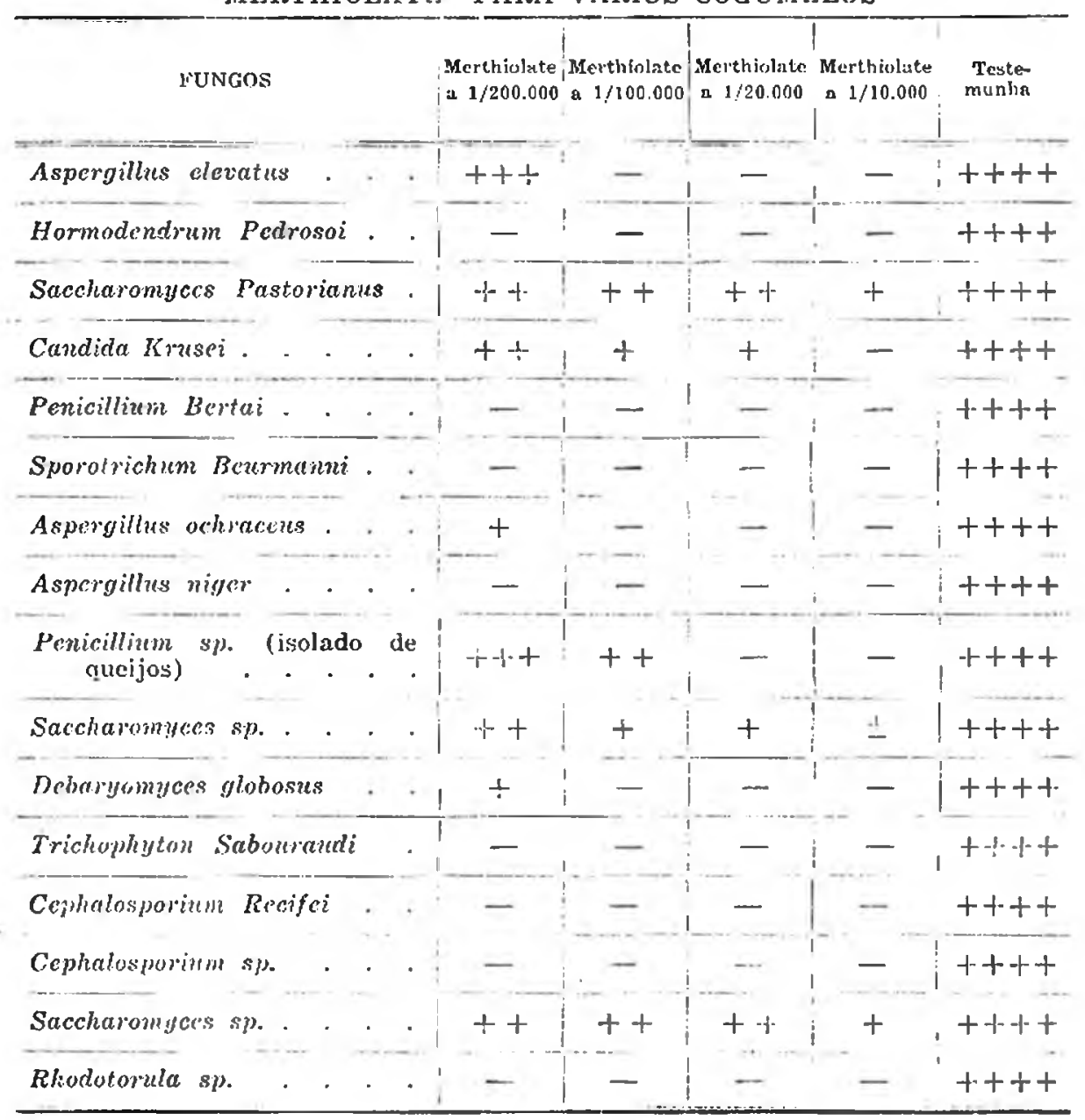


Desejando conhecer a título ilustrativo o comportamento de diversos fungos frente ao "Merthiolate", iniciamos uma série de pesquizas trabalhando com Caldo Sabouraud adicionado do fungistatico diluido a $1: 200.000,1: 100.000,1: 20.000$ e $1: 10.000$.

Os resultados dessas experiências estão relatados no quadro anterior e mostram que, de um modo geral, os bolores sofrem mais intensamente que as leveduras a ação fungistática do "Merthiolate", enquanto o Penicillium isolado dos queijos mostrou-se insensível à droga nas mais altas diluições, outros bolores em condições idênticas tiveram seu crescimento completamente inibido.

Feitas as observações "in vitro" impunha-se verificar qual o comportamento do fungistatico na profilaxia da peniciliose em queijos o que foi feito em laboratório.

Inicialmente, utilizamos queijos logo após a prensagem, sem salga nem tempo de cura que, ou foram imersos numa solução de "Merthiolate" a 1:50.000 em tempos variáveis, ou foram simplesmente pincelados com a solução. Os resultados, depois de 15 dias da inoculação com a amostra do Penicillium isolado, são expressos no quadro seguinte:

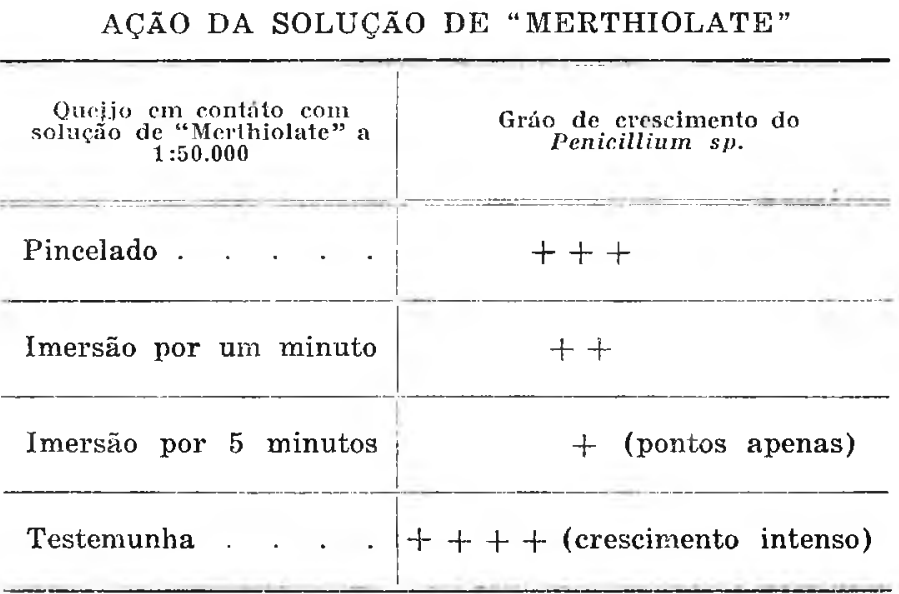

A experiência preliminar citada apontou-nos a imersão dos queijos na solução do fungistático, como procedimento mais eficiente na profilaxia da penicilióse.

Com o objetivo de verificar si o tratamento profilatico devia ser feito antes ou depois da parafinagem para os queijos tipo Minas, habitualmente parafinados na Fábrica Escola "Cândido Tostes", procedemos à observação constante do quadro seguinte. 
INFLUENCIA DE AÇÃO DO “MERTHIOLATE" EM QUEIJOS PARAFINADOS E NÃO PARAFINADOS

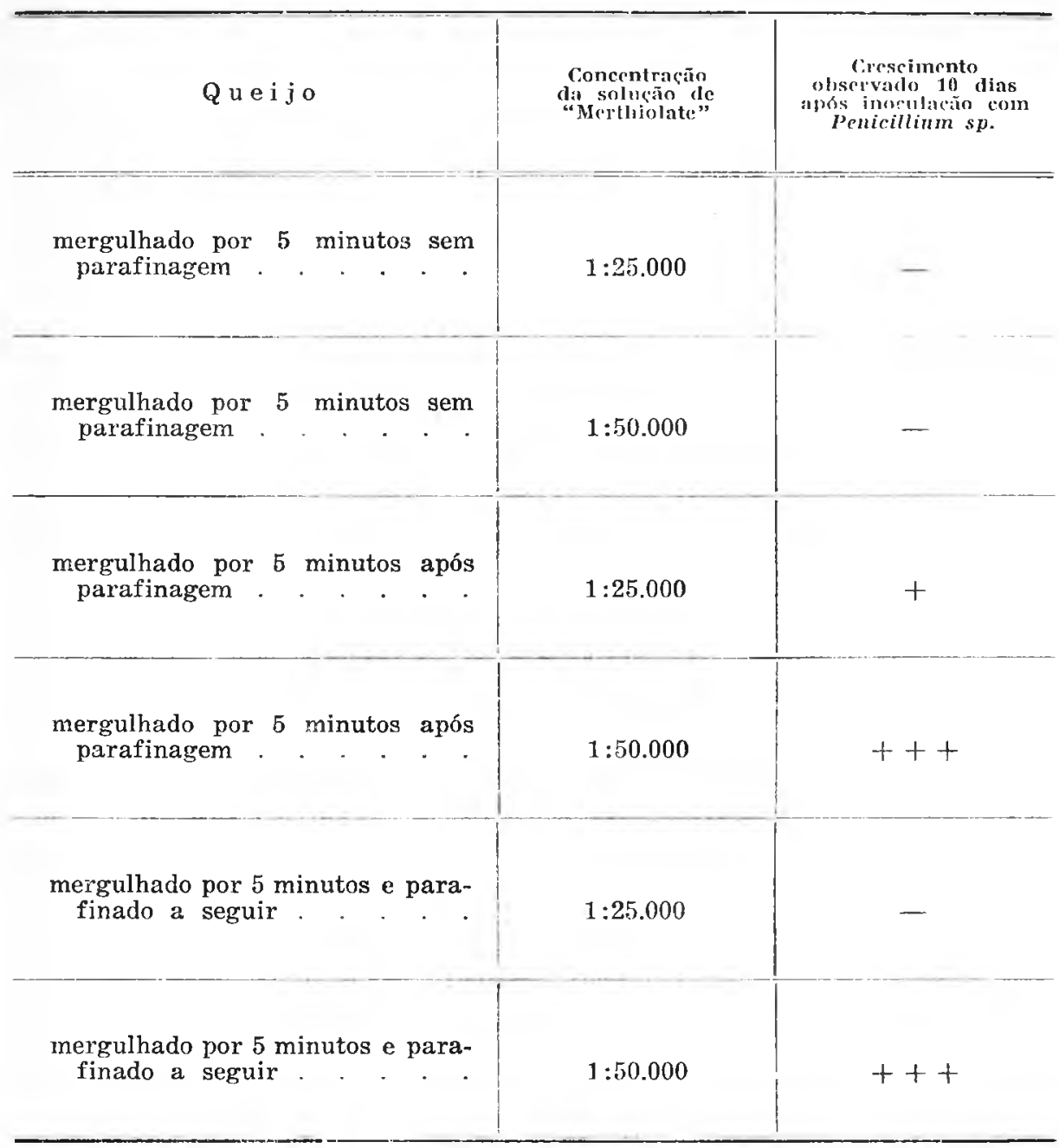

O tratamento dos queijos pelo fungistático deve preceder a parafinagem.

Em queijos que devem ser parafinados, a solução do fungistático só é eficiente a 1:25.000 enquanto para os queijos não parafinados a diluição do fungistático pode ser maior (1:50.000).

Desejando indagar si o contato mais demorado dos queijos com a solução do fungistático a $1: 50.000$ poderia acentuar o poder inibidor, fizemos a experiência do quadro seguinte com fragmentos de um mesmo queijo. 


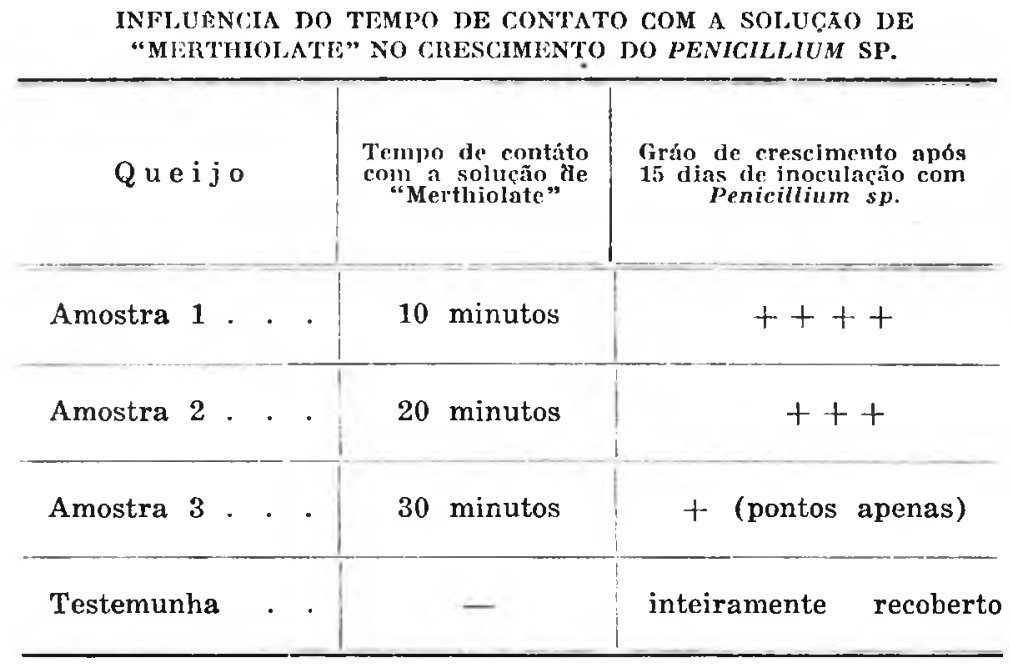

O resultado deste quadro é bem ilustrado pelas fotografias anexas, revelando que quanto mais longo fôr o prazo de contáto entre o queijo e o fungistático maior proteção é conferida ao produto contra a invasão do bolor que isolámos das alterações. (fig. 3).

Convém lembrar que tanto as experiências "in vitro" como as realizadas em laboratório sôbre queijos, são observações preliminares, que necessitam ser ampliadas, para se concluir, em definitivo, da aplicação prática do "Merthiolate" como agente inibidor da Peniciliose em queijos.

\section{CONCLUSÕES}

1 - As alterações de queijos produzidos pela Fábrica Escola de Laticínios "Cândido Tostes" que tivemos oportunidade de examinar foram devidas a um Penicillium $s p$.

2 - Repetidas vezes isolamos êste cogumelo, não só de queijos contaminados, como de parafina e de azulejos; com a amostra isolada reproduzimos experimentalmente com facilidade alterações em tudo idênticas às encontradas naqueles produtos.

3 - Expeziências realizadas "in vitro" evidenciaram que o etilmercuri-tiosalicilato de sódio "Merthiolate" inibe o crescimento do Penicillium isolado de queijos até em diluição a 1:50.000.

4 - De dezesseis amostras de fungos estudados "in vitro" os bolores sofreram mais intensamente do que as leveduras, a ação fungistatica do "Merthiolate".

5 - Para empreender a profilaxia direta da peniciliose, nossas experiências preliminares indicam: 
a - a imersão dos queijos na solução de "Merthiolate" revelouse o procedimento mais eficiente nas condições de nossas experiências;

$b$ - os queijos a serem parafinados devem receber o tratamento por aquele micostatico na concentração de $1: 25.000$ antes da parafinagem;

c - no caso de queijos não parafinados a diluição do fungistático é eficiente mesmo a 1:50.000;

d — o efeito inibidor da solução de "Merthiolate" a 1:50.000 é tanto maior quanto mais longo fôr o tempo de contato com os queijos.

\section{RESUMO}

Os AA., após tecerem comentários acerca da contaminação micótica dos alimentos e, particularmente dos laticinios, passam em revista os principais fatores que condicionam o desenvolvimento de bolores nos produtos. Investigando a causa responsável por alterações apresentadas por queijos produzidos pela Fabrica Escola de Laticínios "Cândido Tostes", em Juiz de Fóra, isolaram um cogumelo do gênero Penicillium, cuja espécie não foi determinada. Com o Penicillium isolado os AA. reproduziram experimentalmente as alterações.

A seguir, passam os AA. a referir os diversos meios empregados na prática, no sentido de prevenir a contaminação dos alimentos por bolores. No caso em apreço, tendo sido feita, sem resultados apreciáveis, a higienização do estabelecimento e respectivas instalações, com os recursos disponiveis, os AA. resolveram estudar, experimentalmente a profilaxia da alteração, agindo sôbre os produtos.

Não foi tentada a aplicação do ácido propiônico e seus sais de cálcio e sódio porque, como observaram diversos pesquizadores esses compostos, para se mostrarem eficientes devem ser usados em concentrações tais que conduzem a modificações das características organoléticas dos queijos, alem de que, o gênero Penicillium é marcadamente mais resistente à ação fungistática dos propionatos.

o trabalho de Turner e col. sugeriu aos AA. a aplicação do "Merthiolate" (etil-mercuri-tiosalicilato de sódio) na preservação da Peniciliose de queijos. As experiências preliminares "in vitro" revelaram que êsse composto tem nítida ação impediente até em diluição a 1:50.000 sôbre o crescimento do Penicillium isolado dos queijos.

Quanto ao comportamento em face do "Merthiolate" de desesseis diferentes amostras de fungos, entre as quais o Penicillium isolado de queijos, os AA. verificaram que, de modo geral, os bolores sofrem a ação fungistática desse composto mais intensamente que as leveduras. 
Passando a ensaiar em laboratório e a título experimental a ação do "Merthiolate" em queijos, os AA. demonstraram que a imersão na solução do fungistatico é o procedimento mais eficiente na profilaxia da Peniciliose.

De experiências posteriores resultou que os queijos a serem parafinados devem receber o tratamento pelo fungistático na concentração a 1:25.000 antes da parafinagem. No caso dos queijos não serem depois parafinados a diluição do fungistatico é eficiente mesmo a 1:50.000. Por último, os AA. verificaram que o efeito inibidor de uma solução de Merthiolate a 1:50.000 é tanto maior quanto mais longo for o tempo de contato com os queijos.

\section{SUMMARY}

The AA. revise the outstanding factors that condition growth of fungi in products, after commenting upon mycotic contamination of food, especially milk derivatives. Upon investigating the responsibility of alterations presented by cheese from the "Fábrica Escola de Laticinios Cândido Tostes" in Juiz de Fóra, they were able to isolate a fungos of the P enicillium genus, its species having not been determined. The AA. were able to reproduce alterations experimentally with the sample isolated.

The AA. proceed to discus the various ways that practice employs in order to avoid food's contamination by fungi. In this case no results were obtained through hygienization of the establishement and its departaments by means at hand. The AA. then made up their minds to study, experimentally, the prophylaxy of the alteration acting upon the products. No use was made of propionic acid or its sodium and calcium salts, because, as been observed by various experimenters, these compounds have to be employed in concentrations such as to determine changes upon the organoleptic characters of cheese. Besides, the genus P enicillium has a markeddly higher resistance to the fungistatic properties of propionates.

The work of Turner and others reminded the AA. the use of "Merthiolate" (ethyl-mercuri-thiosalicilate) in preventing penicilliosis in cheese. Preliminary experiments "in vitro" have shown this compound to have a marked hindering action (when diluted 1:50.000) upon growth of Penicillium isolated from cheese.

The action of "Merthiolate" was observed upon 16 samples of various fungi, among which the $P$ enicillium isolated from cheese; the $A A$. were able to ascertain that, as a rule, molds suffer the fungistatic effects of this compound more intensely than yeasts do. 
Upon essaying in laboratory, with experimental purposes, the action of "Merthiolate" upon cheese, the AA. prove that immersion in a solution of this compound is by far the most efficient prophylactic method bearing reference to penicilliosis. Experiments made afterwards show that have to be treated by "Merthiolate" in concentrations of 1:25.000 before receiving paraffin; the dilution may be weakened even to 1:50.000. The inhibitory effect of this weakened solution is the stronger in direct rate to the time in which it is kept in contact with the cheese.

Practical use of sodium ethyl-mercuri-thiosalicilate (Merthiolate) in prophylaxy of cheese molding in creameris will be the subject of another work.

\section{BIBLIOGRAFIA}

- 1940 - Retarding mold in cheese Nat. Butter and Cheese Jour., 31: 8-12 "in" Jour. Dairy Sci., 23: A 221.

- 1946 - Danger from moldy feed? J. A. V. M. A. 109 (836) : 373-5.

AdaMs, J. - ParfitT, E. H. - 1939 - Some factors influencing the amount of the mold mycelia in butter. Jour. Dairy Sei., 22: 367-74.

Almfida, F. - Lacaz, C. S. - Ribeiro do Vale, L. A. - 1943 - Flora micotica de alguns produtos alimentares. Rev. Inst. Adolfo Lutz, São Paulo, 3 (1): 148-55.

Almeida, F. et al - 1946 - Ação do "Yatren" e do "merthiolate" "in vitro" sôbre o "Paracoccidióides brasiliensis". Arch. Brasil-Med., 36: 41-4.

Brien, R. M. - DeNNE, R. W. - 1945 - Investigations into causes and control of moulds in State houses. New Zealand Jour. Sci. and Technol., 26 B (4) : 174-81 "in" Jour. Dairy Sci., 28: A 120.

Büller Souto, A. - GodoI, O. - Menezes Jr., J. B. Ferraz - 1946 - Investigações microscopicas sobre manteigas. - Rev. Inst. Adolfo Lutz, São Paulo, 4 (1) : 28-49.

Cecilia, C. A. - 1942 - Indústrias lácteas, Madrid, Espasa-Calpe, S. A.

ELLIKER, P. R. - 1944 - A new quantitative method for estimation of total combined length of mold fragments in butter. Jour. Dairy Sci., 27: 369.

Elliker, P. R. - Horrall, B. E. - 1945 - The mold mycelia count as an index of quality of butter. Jour. Dairy Sci., 28: 519-24.

Eмmons, C. W. - 1933 - Fungicidal action of some common desinfectants on 2 dermatophytes. Arch. Dermat \& Syph., 28: 15-21.

FAscetti, G. - 1935 - Burro e formaggio. $4 .^{a}$ ed. Milano, Ulrico Hoepli.

Fleischman , W. - 1945 - Tratado de Lecheria. Trad. 6.a ed. alemana. Barcelona, Editorial Gustavo Gigli, S. A.

GLOBE, E. F. - 1942 - Preventing spoilage by mold and bacteria. Food Indus., 14 (2) : 46-8 "in" Jour, Dairy Sci., 25: A 329.

Golding, N. S. - 1940 - The gas requeriments of "Penicillium Roqucforti" (three strains originally isolated from blue veined cheese) in the presence of nitrogen as diluent and the absence of carbon dioxide. Jour. Dairy Sci., 23: 879-89. 
Gonzalez Ochoa, A. - Ruiloba, J. - 1944 - Acción del propionato de sódio "in vitro" sobre "Actinomyces mexicanus" y "Cephalosporium" sp.; ensayo terapéutico en micetomas producidos por estos hongos. Rev. Inst. Salub. y Enferm. Trop., 5: 83-6.

Hammer, W. B. - 1938 - Dairy Bacteriology. $2^{\text {nd }}$ ed. New York, John Wiley \& Sons, Inc.

INGLE, J. D. - 1940 - Some preliminary observations on the effectiveness of propionates as mold inhibitors on dairy products. "in" Jour. Dairy Sci., 23 : (M 28) : 509.

Irvine, O. R. - Sproule, W. A. - $1940-$ Mold inhibitors for cheese. Canad. Dairy and Ice Cream Jour., 19: (11-19) "in" Jour. Dairy Sei., 24: A 139

JACOBS, M. B. - 1944 - The chemistry and technology of food and food products 2 NewYork, Interscience Publishers Inc.

J ACOBS, M. B. - 1947 - Synthetic food adjuncts. New York, D. Van Nostrand Company Inc.

JAMIESON W. A. - PoWELL, H. M. - 1931 - Merthiolate as preservative for biological products. Am. J. Hig., $14: 218-24$.

JoHns, C. K. - 1941 - Controlling mold growth on cheddar cheese. Canad. Dairy and Ice Cream Jour., 20: (4) "in" Jour. Dairy Sci., 24: A 359.

KEENEY, E. L. et al. - 1943 - Fungistatic and fungicidal effect of sodium propionate on common pathogens, Bull. John Hopkins Hosp., 73: 379-90.

KEENEY, E. L. et al. - 1944 - Propionate und undecylenate ointments in the treatment of "tinea pedis" and in vitro comparison of their fungistatic and antibacterial effects with other ointments. Bull. John Hopkins Hosp., 75: 417-39.

KeENey, E. L. - BroYles, E. N. - 1943 - Sodium propionate in treatment of superficial fungous infections. Bull. John Hopkins Hosp., 73: 479-87.

LEGGATT, A. G. - 1945 -- Testing for yeasts and molds in Butter encourages sanitation. Canad. Dairy and Ice Cream Jour., 24: (1) "in" Jour. Dairy Sci., 29: A 141, 1946.

LEGGE, R. T. - BonAR, L. - Templeton, H. J. - 1933 - Epidermomycosis at University of California. Arch. Dermat.\& Syph., 27 : 12-24.

MACY, H. - ANDERSON A. E. - 1934 - Effect of temperature, salt and acidity on growth of mould ("Oospora Lactis") Nat. Butter \& Cheese Jour., 25: (22) "in" Jour. Dairy Sci., 19: A. 41, 1936.

MACY, H. - OLSON, J. C. - 1939 - Preliminary observations on the treatments of parchement paper with sodium or calcium propionate. Jour. Dairy Sci., 22: 527-34.

MaCY, H. - 1940 - New developments in mold control. Jour. Milk Technology, 3. (2) : 113.

Mallman, N. Z. - 1941 - Mycostatic salts prevent mold growth on stored foods. Food Indus., (7) : 41-42-54 "in" Jour. Dairy Sci., 24: A 355.

Marsiall, M. S. - 1931 - Merthiolate new antiseptic. California \& West. Med., 35: $43-4$.

Oliver, F. -1943 - Lecheria e Industrias derivadas. 2.a ed. Barcelona, Editorial José Montesó.

OLson, J. C. - MaCY, H. - 1940 - Propionic acid and its calcium and sodium salts as inhibitors of mold growth. "in" Jour. Dairy Sci., 23 (M29): 509-10. 
OLson JR., J. C. - MACY H. - 1945 - Propionic acid, sodium propionate and calcium propionate as inhibitors of mold growth. I. Observations on the use of propionate - treated parchment in inhibiting mold growth. on the surface of butter. Jour. Dairy Sci., 28: 701-10.

Olson JR. J. C. - MACY, H. - 1946 - Propionic acid, sodium propionate and calcium propionate as inhibitors of mold growth. 2: Studies pertaining to the active agent responsible for the inhibitory effect the propionates. Jour. Dairy Sci., 29: (3) : 173-80.

ORLA-JENSEN - 1931 - Dairy Bacteriology. 2nd ed. London, J. \& A. Churchill.

Powell, H. M. - Jamieson, W. A. - 1931 - Merthiolate as germicide. Am. J. Hyg., 13: 296-310.

Powell, H. M. - Jamieson, W. A. - 1934 - On merthiolate and fungi associated with ringworm. Proc. Indiana Acad. Sc., 43: 56-8.

ReID, W. H. E. - EDmondson, J. - ARBuckle, W. S. - 1941 - The effect of various factors on mold mycelia in cream and butter. "in" Jour. Dairy Sci., 24 (M34) : 548.

Tном, C. - 1930 - The Penicillia. London, Bailliere, Tindall \& Cox.

Trikojus, V. M. - 1946 - Chemistry of sodium ethilmercurithiosalicylate. Nature, London, 158. (4014) : 472-3.

TuRner, J. S. et al. - 1946 - Tropic-proofing of optical instruments by a fungicide. Nature, London, 158. (4014) : 469-72.

WALDO, J. H. et al. - 1931 - Bacteriological evaluation of some new water soluble organo-mercury compounds. J. Bact., 21: 323-9.

Watson, R. D. - 1943 - Some factors influencing the toxicity of ozone to fungi in cold storage. Refrig. Engin. 46 (2) : 103 "in" Jour. Dairy Sci., 26: A 225. 
P. Mecciolo, C. S. Lecuz P P. Assis Ribeiro, porriciliose em querijos
Reo. Far. Mad. Vet S. paulo. Vol. B. fasc. is Estampu J

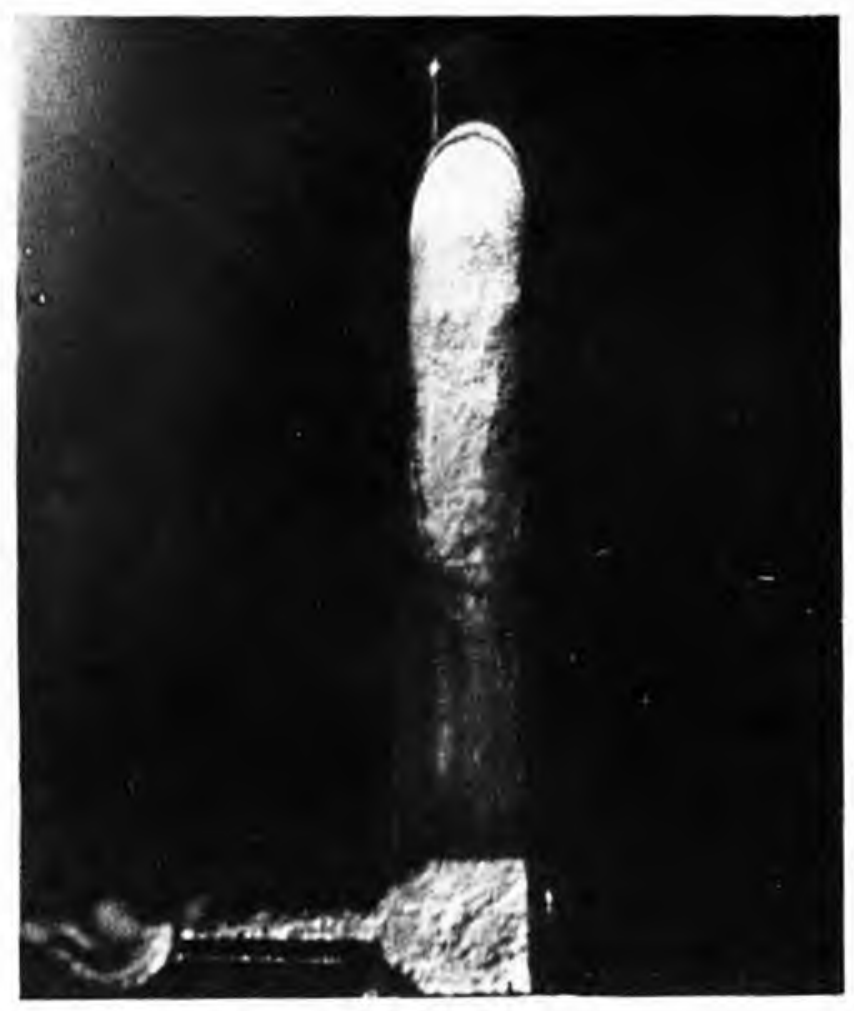

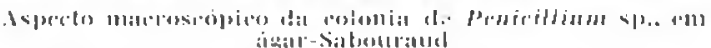

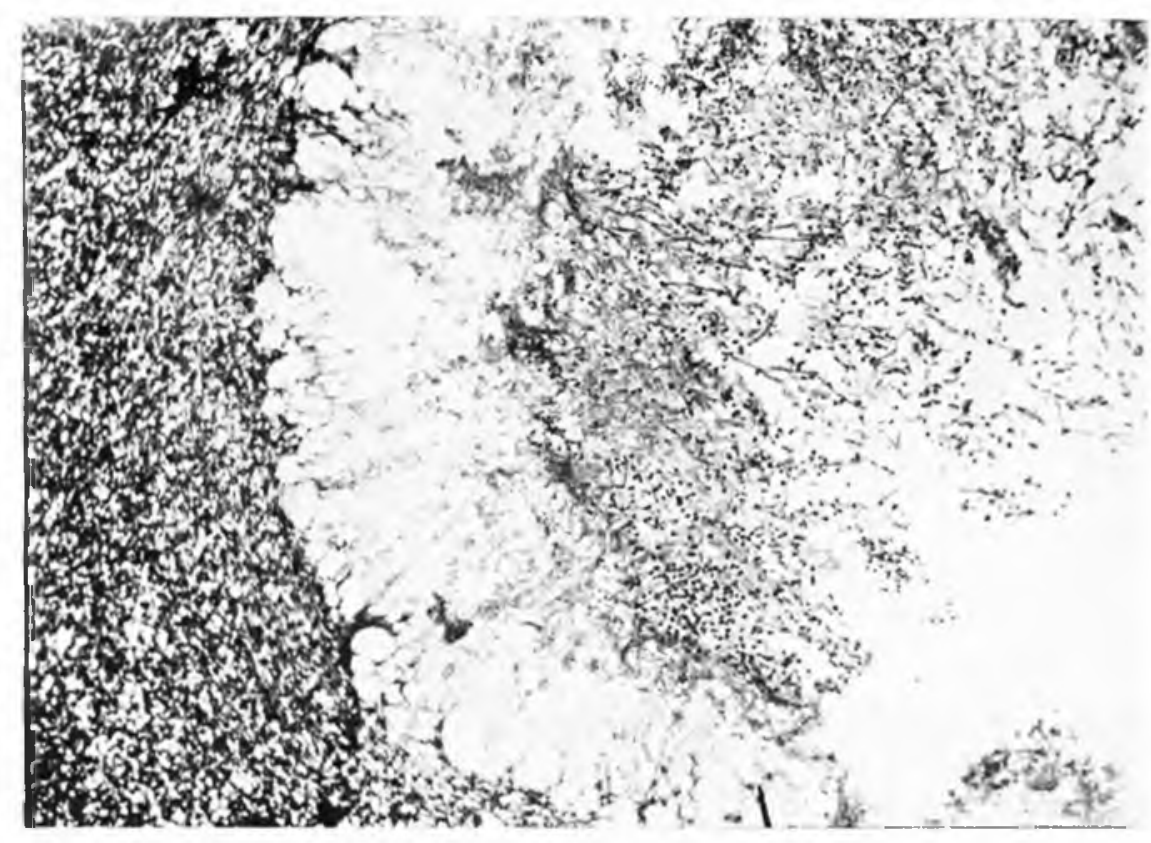

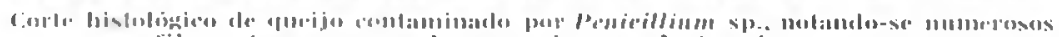

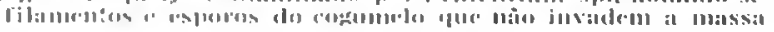


P. Mucciolo, C. S. Lacaz e P. Assis Ribeiro,

Rev. Fac. Med. Vat. S. Panto, Vol. 3. fuse. Peniciliose em queijos

Estampa 11

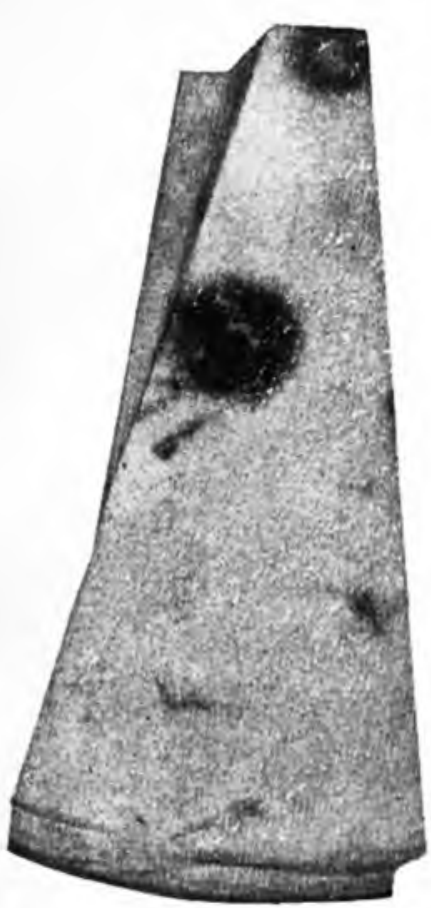

A

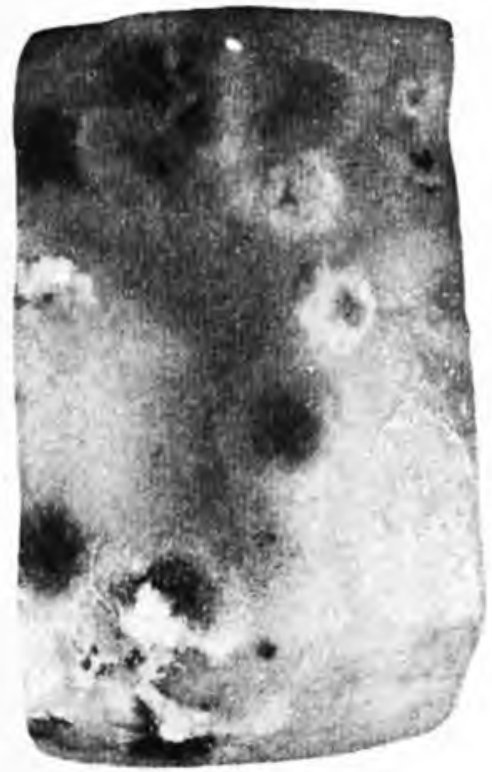

$\mathrm{C}$

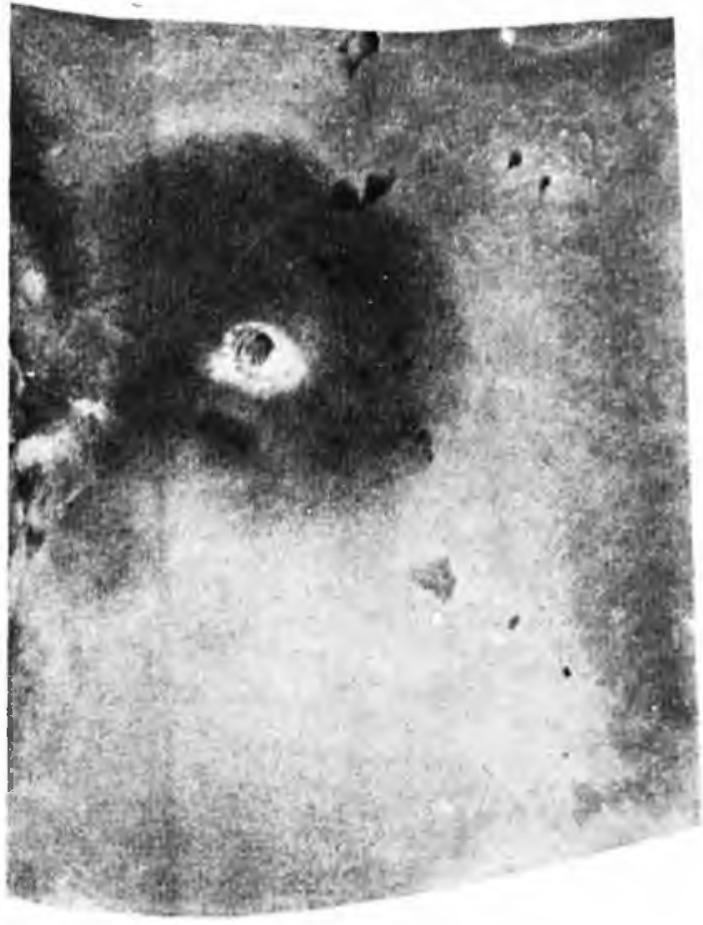

B

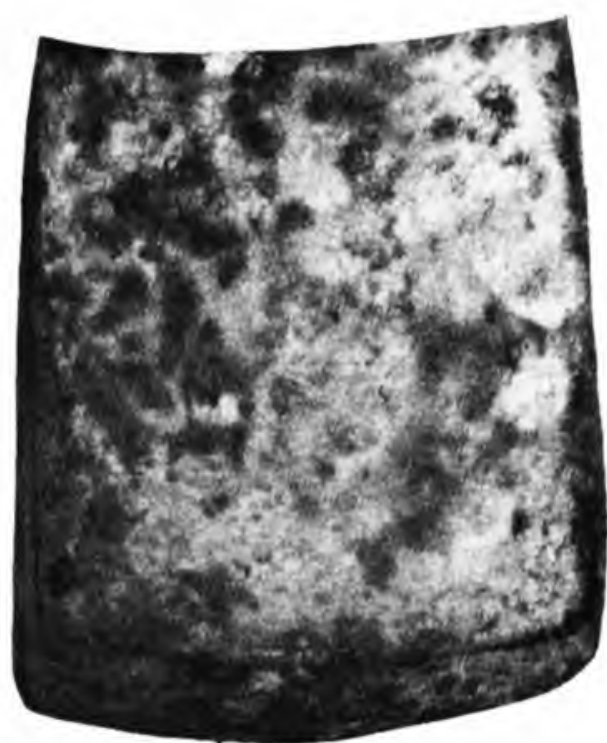

D-Testemunha

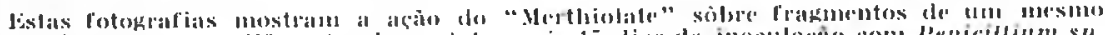

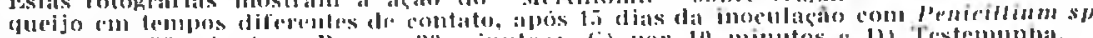

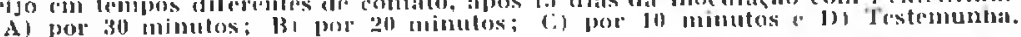

